\title{
Reliability Research Reviewed of Automobile Seat Angle-Adjuster
}

\section{Lei Liu}

School of Automotive Engineering, Shanghai University of Engineering Science, Shanghai, China

Email:810906179@qq.com

How to cite this paper: Liu, L. (2017) Reliability Research Reviewed of Automobile Seat Angle-Adjuster. World Journal of Engineering and Technology, 5, 1-11. https://doi.org/10.4236/wjet.2017.51001

Received: November 18, 2016 Accepted: December 6, 2016

Published: December 9, 2016

Copyright $\odot 2017$ by author and Scientific Research Publishing Inc. This work is licensed under the Creative Commons Attribution International License (CC BY 4.0).

http://creativecommons.org/licenses/by/4.0/

\begin{abstract}
The reliability of the automobile seat angle-adjuster directly affects the safety of vehicle. The reliability of the seat angle-adjuster is improved based on bench test. Liability model of seat angle-adjuster system is established according to seat angle-adjuster of key parts failure mode. That provides technical support for the design improvements of seat angle-adjuster.
\end{abstract}

\section{Keywords}

Automobile Seat Angle-Adjuster, Bench Test, Reliability, Structure

Optimization

\section{Introduction}

With the increase of car ownership in China and the improvement of the speed, traffic accidents also increase year by year. Especially, vehicle collision accounts for about $20 \%$ among the urban road traffic. When the vehicle collision occurs, a larger impact will happen to the vehicle occupants instantly for the sake of huge impact forces [1]. Then, once the failure of seat angle-adjuster happens, instantly, back of occupant will happen under the acceleration function in the opposite direction of driving. When the situation becomes more serious, spinal sprain will lead to paralysis [2]. Under the condition of acceleration, deceleration, turning and braking, a variety of forces acting on driver will cause a periodic alternating shock to the seat back, and this situation has higher demand to the reliability of the seat angle-adjuster [3].

Car seat is both a seat and a protection device, and car seat angle-adjuster is the key component in the seat. The inner ring gear tooth plate and lock are main bearing parts between the back of the chair and the base [4]. In order to adapt to the human body posture, we can adjust the angle between seat and backrest of human body, so as to maximize meet the requirements of comfort and offer 
support for the human body. In emergency situations, in order to guarantee the safety of personnel, seat angle-adjuster parts must have sufficient strength, in addition, a passenger or driver can adjust the seat quickly and easily [5].

Along with our country road traffic conditions improving, increasing car ownership and car speed also gradually increased at the same time [6]. Total is over, traffic accidents, casualties and property losses were caused by the grim situation. So the car running safety has attracted more and more attention [7] [8]. As one of the important parts of the car, car seat plays the role of supporting the driver in place, which ensures that its good field of vision and the performance of vehicle stability control at the same time reduce or avoid the hurt of the driver and crew in accident damage [9]. With the rapid development of automobile industry, the security performance of the car seat already affects vehicle ride comfort and safety, ergonomics, mechanical vibration, control engineering, material science for the integration of systems engineering, such as product [10] [11].

The seat angle-adjuster is the smaller parts of car. In fact, it has great effects on safety and comfort. At the same time, the durability in the actual use process is also one of the most prominent problems. With the constant improvement of test methods, test ability and the quality requirement continuously improving for seat angle-adjuster overall, the quality requirements of car seat assembly and vehicle have improved, which promotes the development of auto industry [12]. The development of automotive technology for safety and comfort of car demand is higher and higher. Now, for high-grade passenger cars, not only the driver seat has been installed with the seat angle-adjuster, but all passenger seats are installed with the seat angle-adjuster, etc. Due to a sharp rise of seat angle-adjuster use and produce scope, auto factory and seat angle-adjuster factory have strengthened the research and test ability of the product continuously, so the research on automotive seat angle-adjuster structure optimization and reliability is of great significance [13].

\section{Seat angle-Adjuster}

Car seat angle-adjuster generally has two kinds of manual and electric drive mode, manual seat angle-adjuster and the handle. Rotating lever seat angleadjuster is a tooth-difference of $2 \mathrm{k}$-h needle swing planetary transmission mechanism, whose adjust function and the self-locking feature set in one, and it has advantages, such as compact structure, convenient operation, small adjust torque and high controlling precision, and easier to motor driver instead, widely used in various types of cars vans seat back angle adjustment. Through establishing mathematical model conforming to the actual working condition, carrying out the optimization design of the product under the theoretical guidance, so as to maximum enhance regulating function on the basis of satisfying its selflocking performance. Double linkage seat angle-adjuster for around two sets of adjustment locking mechanism in a set of institutions under the control action at the same time, the lock at the same time, the locking strength is higher and it 
is applicable to all kinds of buses coach passenger [14]. Due to the safety of car seat, comfort and durability depends largely on the quality and technology level of seat angle-adjuster, so the research on automotive seat angle-adjuster structure optimization and reliability is of great significance [15].

Seat angle-adjuster is the key parts of car seat part to adapt to the human body posture, and adjust the seat and backrest angle of human body, so as to maximize meet the requirements of comfort and offer support for human body. In practical application of seat angle-adjuster, the following aspects need to be satisfied: 1) We should ensure enough parts strength in use process, in emergency situations, for example, when traffic accident occurs, seat angle-adjuster will withstand sudden external shocks, in order to guarantee the safety of personnel, parts must have sufficient strength. 2) When the passengers or the driver adjust seat, it can ensure that users can conveniently adjusted. 3) During the assembly with the car seat, design requirements should meet certain gap [16].

TJL type seat angle-adjuster is $2 \mathrm{k}$-h type one tooth difference cycloid pin gear planetary structure, which makes a good use of the inevitable relationship between efficiency and self-locking, analyzes the self-locking sex from the angle of efficiency, puts forward measures of improving the performance of self-locking and gives improvement results [17].

Reliability is the important indicators of security quality and fatigue life of product. The research areas are related to many fields, such as reliability analysis application on mechanical and electrical design, application of mechanical control, and the simulation application reliability of missile control system. The reliability of the automobile products is closely related to personal safety and economic benefit, only reliability secured, safety, comfort, economy and other performance of automotive can be fully functional. The improvement of reliability can reduce or even prevent the occurrence of failure and accidents, especially prevent catastrophic accidents. Reliability analysis is helpful to optimal design of automobile seat angle-adjuster, so that we can design more perfect seat angleadjusters.

Reliability theory is a comprehensive and borderline science whose main research object is product life features. It involves many scientific fields, such as basic science, technology science and management science. Since the 1960s, the development of space science and aerospace technology has improved the level of reliability research, extended the scope of its research. For the transformation from traditional stochastic reliability based on probability theory to fuzzy reliability based on fuzzy theory, the reliability put forward in recent years makes the theory more rich and perfect [18].

In the past few years, in order to make the reliability of research results be more close to reality, some uncertain factors are included in the scope of study. So reliability analysis method based on fuzzy theory and neural network become a new research method to solve the problem. With the establishment of various new types of complex systems and implementation of the project, the contradiction between traditional reliability design theory and engineering practice has 
been increasingly prominent. Traditional theory of structural reliability design has the following problems: traditional reliability theory is based on common set theory and binary logic. It makes binary state assumption on system state, system either in a totally normal state or in a state of complete failure. This failure line of one size fits all approach is not practical. The traditional theory of reliability design is faced with contradictions between complicated things and describing the nature of things and state accurately. And this kind of traditional ideas and methods of the reliability research needs a fuzzy method to describe the reliability of system. Finally, the traditional reliability design theory lacks of necessary data.

Distribution scheme of random variable and statistical parameters is obtained by the method of fitting and estimate involved in mathematical statistics. The accuracy of experimental result is related to the capacity of the sample, methods of statistical inference and parameter estimation method. Moreover, we may have to get these data through the experiences of experts when lacking of data. For the uncertainty analysis of probability, mainly concentrated in: 1) The calculation of reliability of structure system and the failure mode of the probability are studied for the uncertainty of statistical data, that provides a good theoretical support for numerical evaluation. 2) System reliability is considered the influence of structure fuzzy factors on structural based on the theory of fuzzy reliability. Method of optimal allocation of structure system reliability based on this theory is more practical than normal distribution method. 3) Because the functions used for structure design to actual situation is not fully reflect, and the same function can be represented by different expression, the calculation of reliability of structure will be affected. These studies are more comprehensive to reflect the structural uncertainty. At present, the reliability theory as a useful supplement to the reliability theory is still at the fledgling stage, which needs to be further improved [19].

The overall reliability engineering research in China is still in infancy, especially in the aspect of practical application of reliability engineering which exist a large gap. Therefore, it stills need to make arduous efforts if the reliability research wants catch up with the world advanced level. Today improving the reliability of the product has become the key to improve the quality of products. Therefore in the increasingly fierce competition in the future days, the reliability research will be more and more enterprise value.

\section{Optimization Methods of Seat Angle-Adjuster}

The optimization design method used in the automobile design not only can make the design cycle be shortened, but improve the design accuracy and solve optimal problems which traditional design method can't solve.

1) Mathematical programming method

Large amount of calculation and convergence speed is slow. For a large structural optimization, the algorithm convergence is bad, and the number of iterations is overmuch which will lead to larger workload. The efficiency of structure 
analysis is not high. For the problem of nonlinear, programming is a sequential unconstrained minimization technique, such as multiplier method, penalty function method. The other is a sequence of approximate technique, such as sequential linear programming method and the method of sequential quadratic programming method and cutting plane. The third is the constraint border search the feasible direction method, such as feasible direction method, the gradient projection method and generalized reduced gradient method [20].

2) Guidelines

Structural optimization is mostly according to the engineering experience, and intuition criterion is put forward such as synchronization failure criterion and the full stress criterion. So the application limitation is bigger, but its physical meaning is clear, method is relatively simple, fewer optimization in structure analysis, fast convergence, high computation efficiency.

3) The method of bionics

Bionics method is to simulate the nature evolution algorithm, such as the returns process simulation and neural network. Wide application of genetic algorithm, it can be practical continuous variables and be applied to an integer or discrete variables, even the numeric variables has become a promising method for solving complex optimization problem. But genetic algorithm iteration times and calculation workload is very large.

\section{Bench Test of Seat Angle-Adjuster}

There are many reasons to carry out the reliability test, mainly include: inspiring the potential failure modes, putting forward improvement measures, ensuring that reliability project or system will meet the predefined requirements, comparing estimate failure rate with actual failure rate, monitoring reliability growth, ensuring the safety of the design margin, confirming the weak links of design or component.

1) Reliability demonstration test

Reliability demonstration test type depends on the stage and the maturity of the product. These tests can be carried out in the prototype or developing stage. After significant changes in product design, we can also indicate the reliability of the product whether improved or reduced due to design changes.

2) Reliability appraisal test

Reliability evaluation test is to validate whether the reliability of the product design meets the prescribed requirements or not, to extract the representative products by experiments under prescribed conditions. Reliability evaluation testis used to estimate a design for booking function is acceptable, the product in using process of the vibration, humidity, shock, temperature cycle and other environmental conditions.

3) Reliability acceptance test

Reliability acceptance test is verified that whether the reliability of batch of product meets the provisions. This test method cannot be used for making decision about qualified rate or any other similar values are acceptable. 
4) Reliability research and test

Reliability on prototype must have developed a test environment stress and working stress, to expose prototype design and process defects test, analysis and improvement process. It is difficult for engineers to predict every failure mode that new products technique has brought, so in order to control research and development process, new product design test must be carried out in different period.

\section{Reliability Analysis of Seat Angle-Adjuster}

Due to various random factors in the process of design, produce, and using, the final formation of the product has the character of random reliability index. The true value of reliability index is a theoretical value. According to the sample observations reliability index, estimates value of the true value can be obtained by statistical analysis.

Commonly used reliability indexes include reliability, failure rate, average life, life expectancy and variance, life standard deviation, reliable life, characteristic life, useful life, maintenance and replacement of life, such as life scale degrees, average repair rate, etc.

1) Reliability

Reliability is the probability that product under prescribed conditions and within a prescribed time interval to complete the required function, generally known as $R$, because it is a function of time, so also for record $R(t)$ called the reliability function.

If with random variable $T$ said product work from start to happen failure or malfunction of the time $f(t)$, the probability density, is the product's reliability in certain specified time $t$ :

$$
R(t)=P(T>t)=\int_{t}^{\infty} f(t) \mathrm{d} t
$$

2) Cumulative failure probability

The cumulative failure probability is the probability of unfinished regulation function failure that product under prescribed conditions within a prescribed time interval, also be called unreliability. General notes for $F$ or $F(t)$.

$$
F(t)=1-R(t)=P(T \leq t)=\int_{-\infty}^{t} f(t) \mathrm{d} t
$$

3) Average life span

For irreversible product, it refers to the average time before failure, general notes for MTTF, for repairable product, it refers to the average trouble-free working time, general notes for MTBF. They all said trouble-free time T mathematical expectation $E(T)$.

$$
\bar{t}=E(T)=\int_{0}^{\infty} t f(t) \mathrm{d} t
$$

4) In a reliable life and life

Reliable life is specified by the reliability of the corresponding time. General notes for $t(R)$. The general reliability decreases with the increase of working 
time t. Given the different $R$, there were different $t(R)$

$$
t(R)=R^{-1}(R)
$$

5) The failure rate

Failure rate is the probability that a product has not yet been failure for working some time, and when change the time, a failure may happen per unit time, commonly referred to $\lambda$, it is also a function of time t so also for record, called the failure rate function $\lambda(t)$.

$$
\lambda(t)=\lim _{\Delta t \rightarrow 0} \frac{1}{\Delta t} P(t \leq T \leq t+\Delta t \mid T>t)
$$

It reflects the time $t$ product failure rate as the instantaneous failure rate.

Failure rate of the observed value is within the unit after a moment the failure products and work to change time has not yet been failure the ratio of the number of products, namely

$$
\hat{\lambda}(t)=\frac{\Delta N_{f}(t)}{N_{s}(t) \Delta t}
$$

The average failure rate is to point to in a certain time average failure rate.

\section{Reliability Research Methods}

1) Stress-strength interference model

For mechanical parts, stress is the factor that causes parts failure, strength is the factor that parts resist stress and prevent failure, the relationship between the stress and strength as follows:

Failure will happen when the stress of the parts is greater than strength of the parts.

It is normal when the stress of the parts is less than strength of the parts.

When parts are under cyclic loading, the strength of the parts will deteriorate over time. Its size will decrease as the life extending, and reduce the stress and strength on the life of the parts is the leading role of change over time. As shown in Figure 1, it expresses the life of the parts with the stress changes the relationship

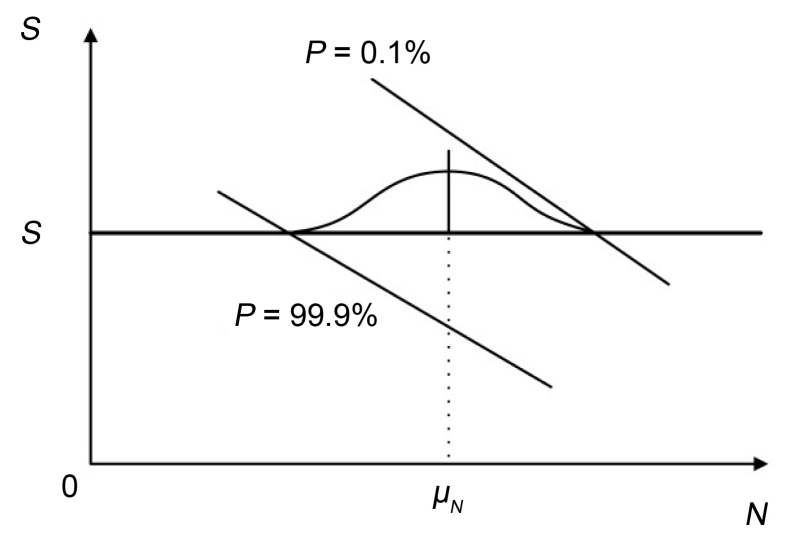

Figure 1. P-S-N curve of component. 
between called P-S-Ncurve [21].

Under a certain stress level, the life is in the form of a certain statistical distribution, mechanical parts are mostly Weibull distribution, normal distribution and lognormal distribution.

2) Probability finite element method

Finite element method is used to solve the numerical analysis, approximate solution of engineering problems in the engineering analysis, and solve all kinds of boundary value problem. Finite element method is widely used in reliability engineering to promote new development of the reliability.

Probabilistic finite element method in linear finite element equation is:

$$
K u=f
$$

Stiffness matrix respectively $K, u, f$ nodal displacement array and the node load array. Stiffness matrix of the:

$$
K=\int_{\Omega} B^{\mathrm{T}} D B \mathrm{~d} \Omega
$$

$B(x), D(x, b), \mu(b), f(b)$ respectively the strain matrix, material performance matrix nodal displacement matrix and node force matrix to coordinate geometry $\Omega$ as the integral domain $D$ is a random function and $\mathrm{f}$ if all the quantities in this equation is decomposed into two parts of the mean and deviation of a random variable, has

$$
(\bar{K}+\Delta K)(\bar{\mu}+\Delta \mu)=\bar{f}+\Delta f
$$

3) Fuzzy reliability calculation method

For the reliability design of mechanical parts, it must be used in the occasion that fuzzy information really exists. In mechanical products, about $80 \%$ of the failure is caused by the wear, so the research of reliability design of wear is very important [22].

A large number of experimental results show that wearing capacitywith specified time can be described by normal distribution. The failure caused by wear is a fuzzy event, that is to say, wear to what extent is a fuzzy concept. On this occasion, we should adopt the fuzzy reliability design [23].

Fuzzy events as allows the amount of wear and tear on the membership function for the ring type the fuzzy reliability for:

$$
R=P(A)=\int_{-\infty}^{\infty} \mu_{A}(x) f_{N W}(w) \mathrm{d} w
$$

3) The competition failure model

Competition failure model is commonly used in reliability statistics model. Because of the complication of its internal mechanism and external environment for larger products, the physical and chemical cause of product failure often has many kinds. The occurrence of any kind of reason will lead to product's ultimate failure. And the cause of the product failure is referred to as the failure mechanism [24].

The product has $m$ failure mechanism $(m>1)$, if any one failure mechanism will lead to product failure says that this product has $m$ failure mechanism of 
competition for the products. If random variable said the failure mechanism of occurrence time have this product for the life:

$$
T=\min \left(X_{1}, X_{2}, \cdots, X_{m}\right), \quad j=1,2, \cdots, m .
$$

This is also equivalent to a $m$ a failure mechanism in series. Set product reliability function is $S(t)$

$$
S(t)=P(T>t)=P\left(X_{1}>t, X_{2}>t, \cdots, X_{m}>t\right)
$$

In many practical problems usually assume that the failure mechanism of time $X_{1}, X_{2}, \cdots, X_{m}$ were independent of each other and set up distribution function for the reliability of the product function can be represented as $F_{i}(t)$ :

$$
S(t)=\prod_{i=1}^{m} P\left(X_{i}>t\right)=\prod_{i=1}^{m} S_{i}(t)
$$

For the competition failure products if the failure rate of the failure mechanism $\lambda_{i}(t)$ the product failure $\lambda(t)$ rate to meet:

$$
\lambda(t)=\sum_{i=1}^{m} \lambda_{i}(t)
$$

\section{Conclusion}

The paper mainly studies the optimization of the design theory and test analysis theory. The reliability analysis for the seat angle-adjuster, optimization and experimental study of key parts provides a theoretical basis. All results of the paper provide a theoretical basis for the reliability of the analysis of the seat angle-adjuster.

\section{Acknowledgements}

This work was supported by the National Natural Science Foundation of China (51175320), Innovation Program of Shanghai Municipal Education Commission (13YZ110), The Teaching Building Project by Shanghai University of Engineering Science (p201406002), The Program for Professor of Special Appointment (Eastern Scholar) at Shanghai Institutions of Higher Learning and the Shanghai Foundation for Development of Science and Technology (10230501500).

\section{References}

[1] De Carvalho, D.E. and Callaghan, J.P. (2012) Influence of Automobile Seat Lumbar Support Prominence on Spine and Pelvic Postures: A Radiological Investigation. Applied Ergonomics, 43, 876-882. https://doi.org/10.1016/j.apergo.2011.12.007

[2] Paul, G., Daniell, N. and Fraysse, F. (2012) Patterns of Correlation between Vehicle Occupant Seat Pressure and Anthropometry. Work, 41, 2226-2231

[3] Alves, C.D. and Sven, D. (2011) Articulation at Shoulder Level-A Pilot Experimental Study on Car Seat Comfort. Applied Ergonomics, 43, 27-37.

[4] Xie, W., Liao, H. and Jin, T. (2014) Maximizing System Availability through Joint Decision on Component Redundancy and Spares Inventory. European Journal of Operational Research, 237, 164-176. https://doi.org/10.1016/j.ejor.2014.02.031

[5] Hegadekatte, V., Huber, N. and Kraft, O. (2005) Finite Element Based Simulation of 
Drysliding Wear. Modelling and Simulation in Materials Science and Engineering, 13, 57-75. https://doi.org/10.1088/0965-0393/13/1/005

[6] Allella, F., Chiodo, E. and Lauria, D. (2004) Optimal Reliability Allocation under Uncertain Conditions with Application to Hybrid Electric Vehicle Design. International Journal of Quality and Reliability Management, 22, 626-641. https://doi.org/10.1108/02656710510604926

[7] Yue, T. and Wahab, M. (2014) Finite Element Analysis of Stress Singularity in Partial Slip and Gross Sliding Regimes in Fretting Wear. Wear, 321, 53-63. https://doi.org/10.1016/j.wear.2014.09.008

[8] Prakash, A., Gnanamoorthy, R. and Kamaraj, M. (2012) Fretting Wear Behavior of Controlled Ball Impact Treated Aluminium Alloy under Dry Sliding Condition. Surface and Coatings Technology, 207, 450-460.

https://doi.org/10.1016/j.surfcoat.2012.07.045

[9] Barrans, S., Blunt, L., Zhang, H., et al. (2007) Reproduction of Fretting Wear at the Stem-Cement Interface in Total Hip Replacement. Proceedings of the Institution of Mechanical Engineers, Part H, 221, 963-971. https://doi.org/10.1243/09544119JEIM333

[10] Xie, L., Zhou, J. and Hao, C. (2004) System-Level Load-Strength Interference Based Reliability Modeling of k-Out-of-n System. Reliability Engineering \& System Safety, 84, 311-317. https://doi.org/10.1016/j.ress.2003.12.003

[11] Zheng, S., Xu, H., Feng, J., et al. (2011) Lightweight Design of Automobile Drive Shaft Based on the Characteristics of Low Amplitude Load Strengthening. Chinese Journal of Mechanical Engineering, 24, 1111-1115. https://doi.org/10.3901/CJME.2011.06.1111

[12] Wang, M., Liu, X., Wang, Y., et al. (2015) Reliability Analysis and Evaluation of Key Parts for Automobiles on the Basis of Dimensional Changes during High-Speed Operation. Journal of Testing and Evaluation, 43, 1464-1471. https://doi.org/10.1520/JTE20140403

[13] Chen, T., Zheng, S., Liao, H., et al. (2015) A Multi-Attribute Reliability Allocation Method Considering Uncertain Preferences. Quality and Reliability Engineering International, 32, 2233-2244. https://doi.org/10.1002/qre.1930

[14] Cruzado, A., Leen, S., Urchegui, M., et al. (2013) Finite Element Simulation of Fretting Wear and Fatigue in Thin Steel Wires. International Journal of Fatigue, 55, 721. https://doi.org/10.1016/j.ijfatigue.2013.04.025

[15] Zhang, T., Harrison, N., McDonnell, P., et al. (2013) A Finite Element Methodology for Wear-Fatigue Analysis for Modular Hip Implants. Tribology International, 65, 113-127. https://doi.org/10.1016/j.triboint.2013.02.016

[16] Henley, E. and Kumamoto, H. (1981) Reliability Engineering and Risk Assessment. Prentice Hall, Upper Saddle River.

[17] Liu, X., Zheng, S., Chen, T., et al. (2016) Durability Testing Method of a Hub Reducer System Based on the Shanghai Standard Road Driving Cycle. Journal of Testing and Evaluation, 44, 665-678. https://doi.org/10.1520/jte20140479

[18] Du H, Li W and Zhang N. (2013) Vibration Control of Vehicle Seat Integrating with Chassis Suspension and Driver Body Model. Advances in Structural Engineering, 16, 1-9.

[19] Ntuen, C.A. and Park, E.H. (1993) A Formal Method to Characterize Robot Reliability. Proceeding Annual Reliability and Maintainability Symposium, Los Angeles, 26-28 January 1993, 395-398.

[20] Leuschen, M.L., Walker, I.D. and Cavallar, J.R. (1998) Robot Reliability through 
Fuzzy Markov Models. Proceeding Annual Reliability and Maintainability Symposium, Anaheim, 19-22 January 1998, 209-214.

https://doi.org/10.1109/rams.1998.653739

[21] Carreras, C. and Walker, I.D. (2000) Interval Methods for Improved Robot Reliability Estimation. Proceeding Annual Reliability and Maintainability Symposium, Los Angeles, 24-27 January 2000, 22-27.

[22] Jeong, U., Kim, Y., Kim, J., et al. (2016) Evaluation of the Rattle Noise of a Vehicle Seat Using the Coherence Analysis Technique. Proceedings of the Institution of Mechanical Engineers, Part D: Journal of Automobile Engineering, 230, 436-446. https://doi.org/10.1177/0954407015586139

[23] Liu, X., Qi, H., Wang, Y., et al. (2016) Reliability Analysis and Evaluation of Differential System Based on Low Load Strengthening Model. Quality and Reliability Engineering International, 32, 647-662. https://doi.org/10.1002/qre.1779

[24] Gavin, H. and Zaicenco, A. (2007) Performance and Reliability of Semi-Active Equipment Isolation. Journal of Sound and Vibration, 306, 74-90.

https://doi.org/10.1016/j.jsv.2007.05.039

\section{Submit or recommend next manuscript to SCIRP and we will provide best service for you:}

Accepting pre-submission inquiries through Email, Facebook, LinkedIn, Twitter, etc. A wide selection of journals (inclusive of 9 subjects, more than 200 journals)

Providing 24-hour high-quality service

User-friendly online submission system

Fair and swift peer-review system

Efficient typesetting and proofreading procedure

Display of the result of downloads and visits, as well as the number of cited articles

Maximum dissemination of your research work

Submit your manuscript at: http://papersubmission.scirp.org/

Or contactwjet@scirp.org 